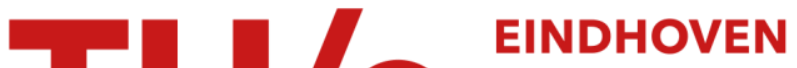

\section{A process synthesis approach for isolation of isoflavones from okara}

Citation for published version (APA):

Jankowiak, L., Mendez Sevillano, D., Boom, R. M., Ottens, M., Zondervan, E., \& Goot, van der, A. J. (2015). A process synthesis approach for isolation of isoflavones from okara. Industrial and Engineering Chemistry Research, 54(2), 691-699. https://doi.org/10.1021/ie5038962

DOI:

10.1021/ie5038962

Document status and date:

Published: 01/01/2015

\section{Document Version:}

Publisher's PDF, also known as Version of Record (includes final page, issue and volume numbers)

\section{Please check the document version of this publication:}

- A submitted manuscript is the version of the article upon submission and before peer-review. There can be important differences between the submitted version and the official published version of record. People interested in the research are advised to contact the author for the final version of the publication, or visit the $\mathrm{DOI}$ to the publisher's website.

- The final author version and the galley proof are versions of the publication after peer review.

- The final published version features the final layout of the paper including the volume, issue and page numbers.

Link to publication

\section{General rights}

Copyright and moral rights for the publications made accessible in the public portal are retained by the authors and/or other copyright owners and it is a condition of accessing publications that users recognise and abide by the legal requirements associated with these rights.

- Users may download and print one copy of any publication from the public portal for the purpose of private study or research.

- You may not further distribute the material or use it for any profit-making activity or commercial gain

- You may freely distribute the URL identifying the publication in the public portal.

If the publication is distributed under the terms of Article 25fa of the Dutch Copyright Act, indicated by the "Taverne" license above, please follow below link for the End User Agreement:

www.tue.nl/taverne

Take down policy

If you believe that this document breaches copyright please contact us at:

openaccess@tue.nl

providing details and we will investigate your claim. 


\title{
A Process Synthesis Approach for Isolation of Isoflavones from Okara
}

\author{
Lena Jankowiak, ${ }^{\dagger}$ David Méndez Sevillano, ${ }^{\ddagger}$ Remko M. Boom, ${ }^{\dagger}$ Marcel Ottens, ${ }^{\ddagger}$ Edwin Zondervan, ${ }^{\S}$ \\ and Atze Jan van der Goot*, ${ }^{\dagger}$ \\ ${ }^{\dagger}$ Laboratory of Food Engineering, Wageningen University, P.O. Box 17, 6700 AA Wageningen, The Netherlands \\ ${ }^{\ddagger}$ Department of Biotechnology, Delft University of Technology, Julianalaan 67, 2628 BC, Delft, The Netherlands \\ ${ }^{\S}$ Department of Chemical Engineering and Chemistry, Eindhoven University of Technology, P.O. Box 513, 5600 MB Eindhoven, The \\ Netherlands
}

ABSTRACT: Owing to the complexity of food matrices, process synthesis methodologies have not been as widely applied in the food industry as in the chemical industry. Here, we describe the application of a process synthesis methodology to design a system to separate valuable components from a byproduct of the soymilk production. The method yielded a number of potential processing pathways and relevant mechanistic questions, which required experimental input. The combination of considering the overall system on the level of general transformations, heuristics, and additional insights through experiments resulted in a simplified conceptual process design for the separation of isoflavones from okara with a globally more sustainable choice. The holistic approach within process design as an implication of the methodology is discussed.

\section{INTRODUCTION}

Food processing must become more sustainable and energyefficient, use nontoxic solvent routes, and make efficient use of raw materials, leading to more natural ingredients and products. On the way toward no-waste processes, the isolation of valuable products from side streams has gained a lot of interest. It is important to consider several factors in this context. While the isolation of valuable components from a relatively low value stream appears attractive, the requirement for sophisticated extraction and purification technologies may reduce the profit margin and lead to an uneconomic outcome. ${ }^{1}$

Additionally, the extra process steps for the isolation of the valuable components should meet modern objectives on good resource use and energy efficiency, and the use of natural, less toxic ingredients and processing aids. To comply with the combination of these constraints, a systematic approach toward such processes is necessary. Here we demonstrate the potential of a process synthesis for the isolation of valuable components from a side stream of soy processing, namely okara. Okara can be considered as a model material for other byproduct streams such as brewer's spent grain or pomace, in which minor components have economical potential as well.

Process synthesis can be described as the activity of the engineer of conceptually designing a process and/or process plant, in other words, building the flow sheet. Traditionally, the term is coming from the chemical engineering area, describing the design of entire chemical process plants. Therefore, process synthesis methodologies, aiming at a systematic approach of designing the process, were developed mainly for chemical products, until the similarities between chemical consumer goods and structured food products were recognized. ${ }^{2-6}$ The latter explains the growing interest of the food industry to translate conceptual design methodologies from the chemical sector into the food sector. However, the process synthesis methodologies have to be updated concomitantly because of the dynamics within the industry, such as a shifting product portfolio, new economic situations, new regulations, and sustainability concerns. ${ }^{7-10}$ The main challenges for the food industry are described by Meeuse ${ }^{11}$ and Bongers and AlmeidaRivera. ${ }^{12}$ The complex matrix of a typical food material plus the manifold interactions between food components complicates the systematic synthesis of processes, because of the difficulty of quantitatively capturing those aspects in mathematical models among others. Consequently, a product-driven process synthesis methodology was developed for the design of structured products, which was successfully applied by Gupta and Bongers $^{13}$ for the redesign of a Bouillon cube production process. However, until this moment, this approach has not yet been applied for the design of processes aimed at utilization of side streams.

In this paper, we extend the concept of the product-driven process synthesis methodology to the isolation of valuable components from a side stream, which in essence means the design of a separation and isolation process. In previous examples on product assembly, the challenges were to influence the interaction between the ingredients while processing and to predict the resulting texture and other properties of the food product according to the consumer's liking. The challenges faced in the development of a separation process are discussed by Jankowiak et al. ${ }^{14}$ There, it was demonstrated that the effect of an extra processing step on the outlet streams is also difficult to predict, again due to the behavior of interacting components and the thermodynamic and kinetic behavior of the system. A further challenge arises from the fact that additional components, such as extraction solvents, have to be introduced to perform a certain separation that often introduces new impurities and may require additional processing steps.

Received: October 1, 2014

Revised: November 26, 2014

Accepted: December 23, 2014

Published: December 23, 2014 
For this study, we used okara as a model material. Okara is a byproduct of soymilk production, which contains mainly fibers, proteins, and fat. ${ }^{14,15}$ Among the minor components, okara contains isoflavones. ${ }^{16}$ They belong to a group of polyphenols, which reportedly play an important role in human health, ${ }^{17}$ and which therefore have considerable value.

\section{THEORY}

Process Synthesis Methodology. To facilitate the process development, we adapted a process synthesis methodology based on Bongers and Almeida-Rivera. ${ }^{12}$ These authors suggested a new methodology combining product and process synthesis based on a process systems engineering strategy. Their methodology is based on an approach of Douglas, ${ }^{18,19}$ which simplifies the complexity of the problem by dividing the problem into several hierarchically ordered levels. Starting with very generic definitions and network structures, more detailed and local decisions are required at each level, which allows the user to go strategically from one level to the next one. As knowledge about the system increases, the designer can fill in more detail at each level, and with this go from generic transformations and a very rough network of physical or chemical transformations all the way toward a complete feasible flow sheet alternative. An important component of this methodology is aimed at the generation and screening of alternative flow sheets. Conceptualization retards the fixation of a flow sheet, which reduces the risks of irreversible and suboptimal decisions during the design of the process.

The methodology uses a stepwise design method over several levels, which are summarized in Table 1 and discussed in more

Table 1. Levels of the PDPS Methodology

\begin{tabular}{cl} 
level & \multicolumn{1}{c}{ description } \\
0 & framing \\
1 & consumer wants \\
2 & product function \\
3 & input-output \\
4 & task network \\
5 & mechanism and operational window \\
6 & multiproduct integration \\
7 & equipment selection or design \\
8 & multi product-equipment integration \\
\hline
\end{tabular}

detail in Bongers and Almeida-Rivera. ${ }^{12}$ The first three levels (0-2) deal mainly with marketing questions, the business context, the project background and the needs of the consumer, which are translated into product properties. In our case of the isolation of valuable minor components, the focus is at the levels of "input-output", after which "task networks", and "mechanisms" can be further derived. When the input and output level is defined, fundamental task networks are listed and evaluated based on heuristics, literature, and experimental work. In the following level, mechanisms are selected that can fulfill the defined tasks. At this stage, it should be pointed out that "tasks" and mechanisms should not be mistaken for unit operations, which, if selected, would lead the designer in an already defined direction. The repeated revision of levels defines the process in more depth, leaving the equipment selection and design to the final step. The methodology combines conventional product design and process design into product-oriented process syntheses as it has been the trend within the last two decades. ${ }^{7,10,20-22}$
The Case Study Okara. Okara a byproduct from soymilk production, contains about $80 \%$ moisture. The dry matter of okara consists of insoluble fiber (with high water binding capacity) and other insoluble and soluble components such as proteins and sugars. Currently, okara is used as animal feed or discarded as landfill, which will become unacceptable from an economic and environmental point of view due to an increased scarcity of resources, and more and more stringent environmental regulations. Consequently, okara has to be upgraded for use as food or nonfood applications, or to be separated into pure or enriched fractions of valuable components. The main valuable components in okara are isoflavones, which belong to a large group of polyphenols. Twelve main chemical forms of the isoflavones are identified in soy and okara, classified in four groups, aglycones, glucosides, acetyl-glucosides, and malonylglucosides. ${ }^{23}$ In okara, the main groups present are the aglycones, glucosides, and malonyl-glucosides and are thus the focus of this study. ${ }^{16}$ The glycosidic forms are the dominant isoflavone form in the raw material, the soybeans, and can be transformed into the other forms under certain processing conditions. $^{24,25}$ The isoflavones' structure and an estimation about their hydrophobicity by the $\log \mathrm{D}$ value (www. chemicalize.org) $)^{26}$ are shown in Table 2.

Extraction of the isoflavones requires a novel separation process with minimal environmental impact. Unfortunately, the design of this process is hindered by the lack of clarity about the embedding of the isoflavones in the okara matrix. Theoretically, the isoflavones can be bound in three different manners: (1) isoflavones are dissolved in the water that is bound by the matrix; (2) isoflavones form (soluble) complexes with the soluble proteins; (3) isoflavones are bound to the (insoluble) biopolymer matrix.

It is even possible that isoflavones are present in all three forms, because isoflavones consist of a mixture of components with different properties (e.g., hydrophobicity).

The recovery of valuable compounds from food byproducts is typically conducted in five distinctive stages. Depending on the desired component, the stages involve a macroscopic pretreatment to prepare the matrix for the following steps, a first separation of micro- and macromolecules, for example, by ultrafiltration or alcohol precipitation, extraction with solvents, purification with, for example, affinity-based processes, and the final formation of the product (e.g., by freeze-drying). ${ }^{27}$ Therefore, in the case of the recovery of isoflavones from okara, one would suggest-in a traditional manner-the following route for separation: First, a solvent would be selected to further solubilize the isoflavones, but the high moisture content of okara limits the freedom in solvent selection, or leads to the requirement of high liquid-to-solid ratios. To increase the freedom for solvent selection, okara can be dried, after which the solvent extraction can be performed using the optimal solvent. Then the solid components would be removed through filtration or centrifugation, leading to a clear solution with soluble components only. Finally, the components would be further purified, most likely with an affinitybased process (e.g., with adsorbents or liquid-liquid extraction). A consequence of this design is the use of large solvent quantities leading to drying and recycling of large liquid streams. Most likely, alternative processes can be designed that are more efficient in energy and solvent use. In this paper, we describe how a process synthesis methodology can be used to derive other alternatives and how this methodology interacts with the input from experiments. 
Table 2. Main Isoflavones Present in Okara, Their Structure and Distribution Coefficient $(\operatorname{logD})$ at $\mathrm{pH} 7$

\begin{tabular}{|c|c|c|c|c|c|}
\hline Group & Isoflavone form & R1 & $\mathbf{R 2}$ & Chemical structure & $\begin{array}{c}\operatorname{logD} \\
(\mathrm{pH} 7)^{\mathrm{a}}\end{array}$ \\
\hline \multirow{3}{*}{ Aglycones } & Daidzein & $\mathrm{H}$ & $\mathrm{H}$ & & $\approx 2.02$ \\
\hline & Glycitein & $\mathrm{COH}_{3}$ & $\mathrm{H}$ & & $\approx 2.33$ \\
\hline & Genistein & $\mathrm{H}$ & $\mathrm{OH}$ & & $\approx 2.67$ \\
\hline \multirow{3}{*}{ B-glucosides } & Daidzin & $\mathrm{H}$ & $\mathrm{H}$ & & $\approx 0.45$ \\
\hline & Glycitin & $\mathrm{COH}_{3}$ & $\mathrm{H}$ & & $\approx 0.29$ \\
\hline & Genistin & $\mathrm{H}$ & $\mathrm{OH}$ & & $\approx 0.80$ \\
\hline \multirow{3}{*}{$\begin{array}{l}\text { Malonyl- } \\
\text { glucosides }\end{array}$} & Malonyl-daidzin & $\mathrm{H}$ & $\mathrm{H}$ & & $\approx-2.25$ \\
\hline & Malonyl-glycitin & $\mathrm{COH}_{3}$ & $\mathrm{H}$ & & $\approx-2.40$ \\
\hline & Malonyl-genistin & $\mathrm{H}$ & $\mathrm{OH}$ & & $\approx-1.60$ \\
\hline
\end{tabular}

${ }^{a}$ Data obtained from chemicalize.org. ${ }^{26}$

\section{MATERIALS AND METHODS}

For most of the experimental and theoretical work accompanying the process synthesis described in this paper, we will refer to our previous studies. ${ }^{14,16,28-30}$ With the experimental work described in this section, we tested the simplified approach for a process with combined tasks.

Okara Production. For experimental data, okara was produced with an ASC50 soymilk system (ProSoya Inc., Ottawa, Canada) as described by Jankowiak et al. ${ }^{29}$

One-Step Separation. For lab-scale experiments, $160 \mathrm{~g}$ of crude okara with a moisture content of $78 \%$ was mixed with water in a ratio of $20 \mathrm{~g}$ of water to $1 \mathrm{~g}$ of dry matter (okara). The mixture was stirred at $500 \mathrm{rpm}$ for $1 \mathrm{~h}$ at room temperature. Subsequently, $3.7 \mathrm{~g}$ of Amberlite XAD7HP resin (Sigma-Aldrich Co., Schnelldorf, Germany) was added on top of the plunger (see Figure 1), which had a mesh small enough to keep the okara and resin separated for later elution of the resin. The resin was then immersed in the liquid and the mixture was left stirring at $900 \mathrm{rpm}$ overnight for adsorption. After the resin was removed, it was washed with Milli-Q water,

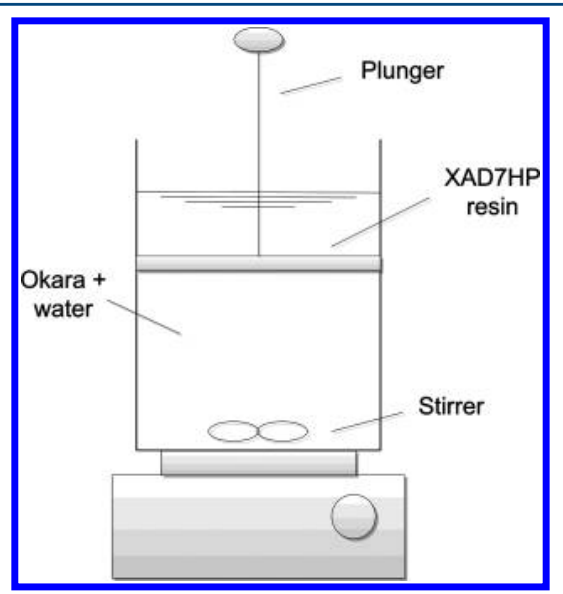

Figure 1. Experimental setup for integrated extraction-adsorption. and the wash water was kept for analysis. The washed resin was immersed into $96 \%$ ethanol (50\% of the amount of water used for extraction), and the liquid was stirred for $3 \mathrm{~h}$ at $50 \mathrm{rpm}$. Samples for the determination of the solids content and for the isoflavone analysis were taken at each step during the entire process.

Isoflavone Analysis. Samples for isoflavone and solids determination were treated and analyzed as described by Jankowiak et al. ${ }^{29}$ Acidified Milli-Q water and acetonitrile were used as eluents to separate the isoflavones on a Waters Atlantis $\mathrm{dC} 18$ column $(3 \mu \mathrm{m}, 2.1 \mathrm{~mm} \times 150 \mathrm{~mm})$. The detection wavelength was $254 \mathrm{~nm}$.

\section{RESULTS AND DISCUSSION}

Many current processes comprise several steps and require more than one solvent. To contribute to the general aim of a more sustainable food production, the use of chemicals and solvents, energy, and the production of waste has to be limited or avoided. Optimized and simplified processes can be one way to achieve such goal. In this section, the process design and resulting process options based on the mentioned process synthesis methodology are described starting at the inputoutput level.

Input-Output. Evaporation and distillation are inefficient processes regarding energy use, as also shown in this case study. ${ }^{28}$ Previous research on the suitability of different solvents for the extraction of isoflavones from okara led to the insight that (i) water as solvent can extract isoflavones reasonably well, with preference for the glycosidic forms of the isoflavones, which are naturally present in nonmodified soybeans. ${ }^{31}$ However, water also leads to swelling of the okara matrix and can disperse or even solubilize other biopolymers with the isoflavones, such as the fibers and proteins, respectively. (ii) Ethanol is an especially good solvent for the aglycone form (a form, which is a result of a hydrolysis reaction during extraction of the soybeans with water) and prevents swelling of the matrix. However, the high viscosity and a possible glassy state of the okara matrix at low water content may inhibit the release of the isoflavones. 


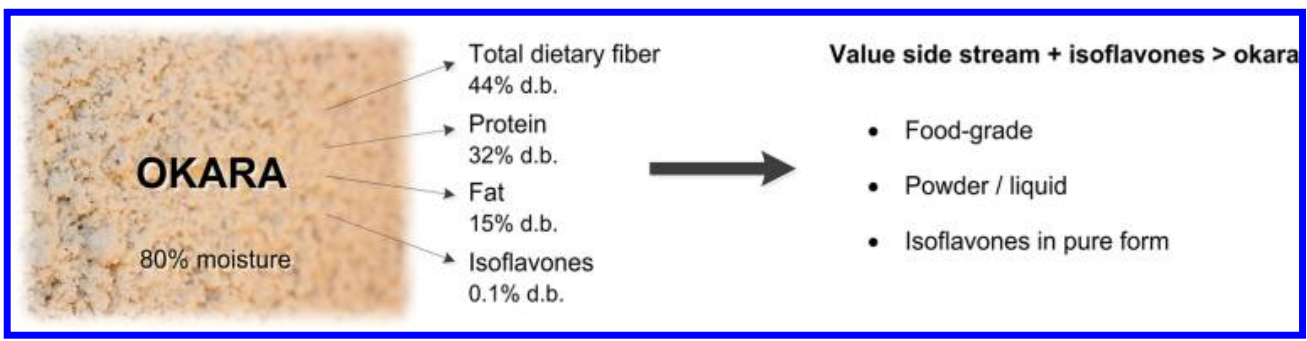

Figure 2. Input-output definition in the case of okara utilization through separation of isoflavones.

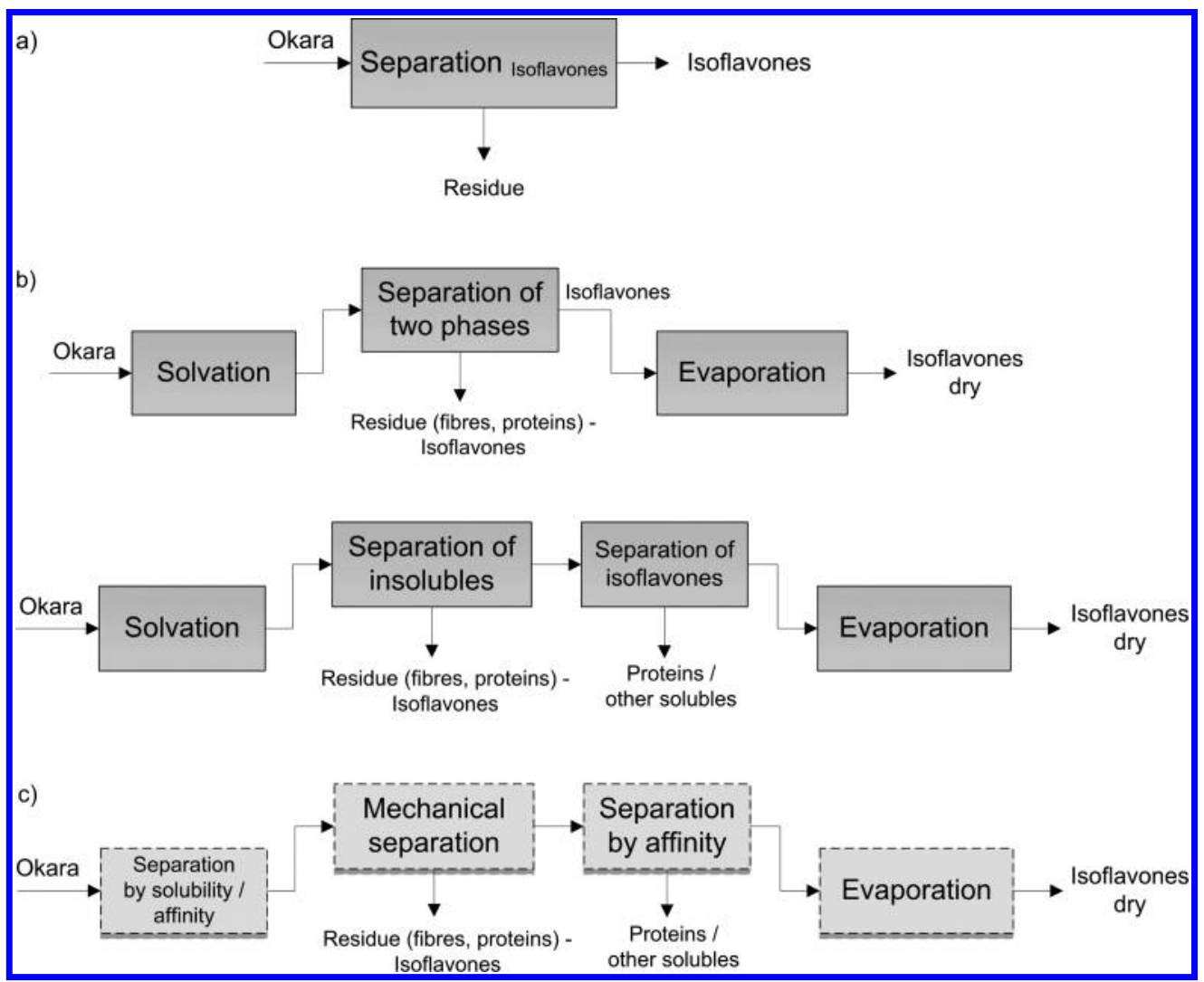

Figure 3. (a) Simple task network, (b) more defined task networks, (c) mechanisms.

A mixture of both solvents may solubilize all isoflavones, prevent extreme swelling of the matrix, and minimize the solubilization of other components such as sugars and peptides. We limited ourselves to ethanol and water as being the most nontoxic and food-grade polar solvents. However, using ethanol will imply the need for a process to remove the ethanol from the raffinate, for example by evaporation/distillation, may complicate the maintenance of safety around the process, and will induce an extra cost for using this solvent.

These disadvantages, and the theoretical and experimental indications that most of the isoflavones are at least somewhat water-soluble, led to further investigation of okara and its isoflavones in the pure water phase. ${ }^{29}$ The experimental input will be further discussed in the following subsection (Task Networks and Mechanisms).

The input of the process is defined in more detail along the entire development of the process. The input stream (raw material) is obviously the byproduct okara. While this material in fact is highly structured, and contains many components, we will here limit its definition to the major components of okara (Figure 2).
The quality and composition of the output depends on the type of solvent and the extraction procedure. It is often suggested that a higher purity may result in a higher economic value. However, this does not necessarily need to be the case. In a more conventional approach, the only optimization route aims at increasing yield and in the case of separation processes high purity. It is questionable whether high purity combined with high yield should be and can be the primary process aim in future processes, especially if the resulting byproducts have to be reduced or further upgraded. In the case of okara, this means that the residue has to be upgraded in a different manner. New objectives such as the sustainability of a process and products can lead to trade-offs in other objectives. To conclude, the information above suggests that three aspects of the optimal point of process design exist: (i) the purity of the product (fraction), (ii) the yield from the raw material, and (iii) the sustainability or environmental impact of the isolation process:

(i) The yield from the raw material is most important when the isolate has a very high value, and when it is important that the raw material has no residue afterward. In this case, the okara is a stream that does not have much value. All isoflavones that 
are recovered have value. Therefore, this value is proportional to the yield: to go from $90 \%$ recovery to $95 \%$, only gives $5 \%$ increase in income. From a different perspective, to go from $90 \%$ to $95 \%$ recovery, the residual content in the feedstock has decreased by a factor two, implying a much more severe isolation process and subsequently much higher cost of isolation.

(ii) The product quality is closely coupled to the purity in this case. A product containing a lower purity and still containing protein and carbohydrates will have a lower value than an isolate with higher purity. However, for many applications (e.g., as food ingredient) very high purity is often not needed.

(iii) The sustainability of the process is relevant after the product is ensured to have the right specifications (good purity), and the process economics is reasonable. Therefore, the sustainability of the process is a target that is optimized when both the product purity and the yield are defined.

It is important to mention that optimizing those aspects has to be performed in an iterative way. Within each level of the methodology, several options are tested and reported, and decisions are made. A final decision allows moving to the next level. However, the method also implies retreating to an earlier level to refine or redefine decisions made earlier. In fact, the levels have to be dealt with also in an alternating way to achieve an optimal global solution. Previous work showed that water can be a feasible solvent for extraction. ${ }^{29}$ It yields slightly less isoflavones, but leads to a more efficient extraction regarding sustainability of the process and a much more simplified process design. Furthermore, ethanol is 400 times more expensive than water. Therefore, substituting ethanol or other solvents ${ }^{32-34}$ in the extraction step should automatically lead to a more economic process. Each level and iteration within the process development includes the very important economic evaluation. Knowing production rates of okara and its composition, a first rough economic evaluation for the business case could be done taking okara as the input and isoflavones (and their market value) as output. The evaluation showed that it will be difficult to make this a strong case by only recovering isoflavones. Isoflavone isolates have a certain market value, and if we assume that the okara does not have any value and has to be treated as waste, recovering valuable components such as isoflavones seems to represent a good business case. However, when okara can be valorized as animal feed, the economic analysis shows that it is only worth proceeding for the following two cases: first, isolation of isoflavones and purified proteins (as ingredients), and second, the isolation of isoflavones while leaving the rest intact for use as animal feed. The latter excludes the use of solvents that lead to residuals in the remaining material, and points in the direction of water as a solvent. This will generate maximum value when considering the creation of the isoflavone isolate without the loss of value of the okara. In general, it is essential that all fractions must be utilized to generate value when upgrading side streams. Isolating a valuable fraction while destroying the value of the rest will not result in a feasible processing system.

Task Networks and Mechanisms. After defining the input-output level, task networks were built based on several hypotheses (see, for example, the Theory section). Some selected task networks are shown in Figure 3.

The first and simplest task network (Figure 3a) had to be defined further in more detail. Therefore, we developed sequences of possible tasks. At this stage, the most promising task networks are selected, along with a list of mechanisms needed to fulfill this task (an example is given in Figure 3c). This is not a sequential procedure, but the process of building task networks and the evaluation of separation mechanisms is iterative, if necessary, with additional input from experimental work. Furthermore, the experimental exploration is also important for finding new and unexpected, and more sustainable processes.

Following the classical route, different ethanol-water fractions ranging from $0 \%$ to $90 \%(\mathrm{w} / \mathrm{w})$ ethanol were tested as solvents for the extraction of isoflavones from crude and from dry okara. ${ }^{16}$ An intermediate ethanol concentration (between $50 \%$ and $80 \%$ ethanol) gave the best extraction yield and purity of isoflavones in the extract. Nevertheless, the purity (isoflavones per dry weight extract) still did not exceed $1.4 \%$, and further purification is required for a more concentrated isoflavone product that can be used for example as a health ingredient in food products. The evaluation of the different solvents for extraction gave information on the matrix, which means its swelling behavior, the affinities of the isoflavones toward the matrix, and the ability of other components to dissolve. The solubility of some of the isoflavone forms is lower in water than in ethanol or ethanol-water mixtures, which is a consequence of the finding that some types of okara have unnaturally high contents of aglycones, which is a consequence of the soymilk process.

The presence of those components explains why ethanol or aqueous ethanol is often considered as a preferred solvent. ${ }^{35}$ However, a further analysis showed that one has to differentiate between the aglycones and glycosides, since their different natural structures, and therefore polarity and hydrophobicity, lead to their different extractive behavior. The aglycones have a much lower solubility in water than in ethanol, ${ }^{16,36}$ and the cosolubilization of other components makes aqueous ethanol the preferred solvent. However, after the extraction of the isoflavones from okara, they have to be isolated from the extract. A suitable mechanism to separate phenolic compounds such as isoflavones from a solvent mixture is using specific affinity (e.g., based on hydrophobicity). Therefore, the affinity of the different isoflavone groups to chromatographic resins depending on the solution they are dissolved in, was evaluated. ${ }^{30}$ Isoflavone extracts produced with ethanol/water mixtures ranging from $0 \%$ to $80 \%$ ethanol were tested for their adsorption on different resins, and our assumption was confirmed that affinity toward a resin was the largest when the components are dissolved in water. This leads to the conclusion that, if including the isolation (adsorption) step, it is not optimal to use an ethanol-containing extractant. Water, being a relatively poor extractant, makes the subsequent isolation much easier. The holistic approach of including both steps points to a different optimal process design.

To summarize, when keeping further purification of the extract in mind, it could be concluded that each step has its own optimum conditions, which are not the best conditions for the overall process. For the extraction, an ethanol concentration of around 50\% was optimal, but for isolation by adsorption, the water extract gives the most efficient process.

A trend in process design is toward the integration of process steps as it leads to simplification and often more efficient and economic processes. ${ }^{8,37}$ It is well-known that solvents are the most detrimental part to the efficiency of processes, since they tend to leave residues, and parts of them are often emitted to the environment. An isolation step, for example by chromato- 


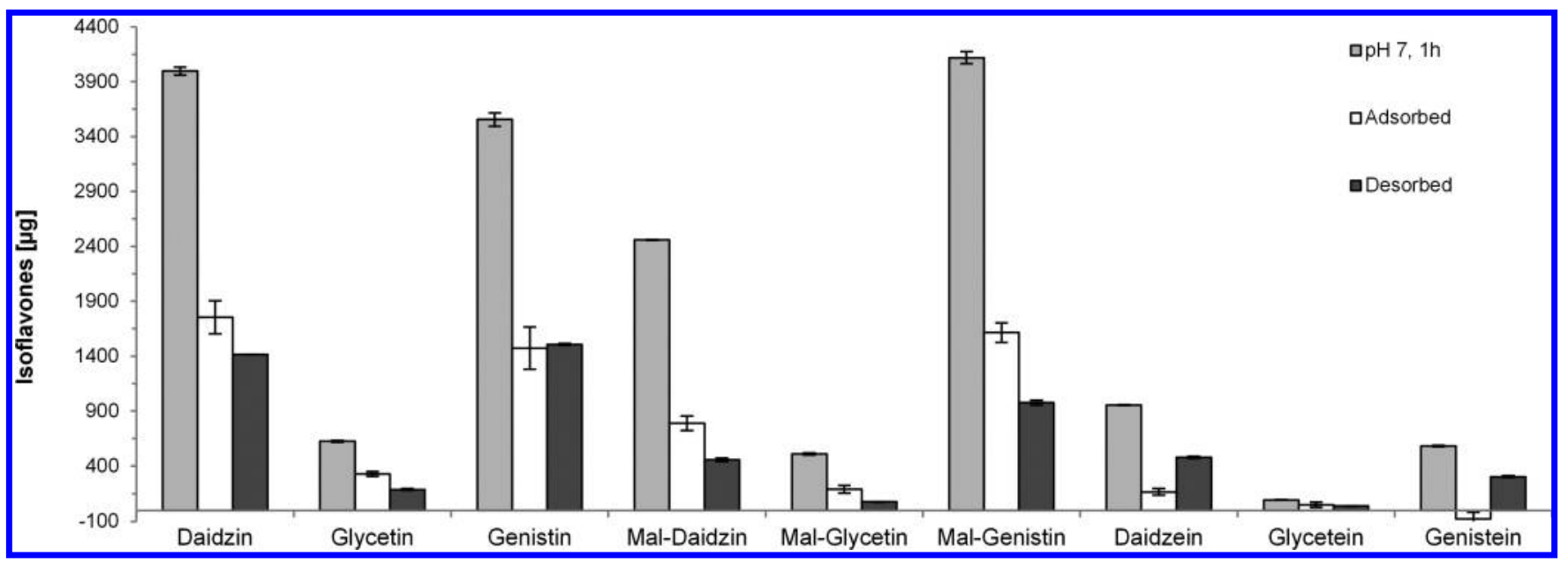

Figure 4. Isoflavones $[\mu \mathrm{g}]$ in liquid before adsorption, calculated amount of isoflavones $[\mu \mathrm{g}]$ adsorbed, and isoflavones $[\mu \mathrm{g}]$ desorbed.

graphic methods, is indispensable to reach highly purified isoflavones. Therefore, instead of optimizing both processes themselves, we evaluated the entire system and concluded that a water-based extraction could be integrated with the subsequent chromatographic purification. Solvents are an important factor determining the efficiency of a process, and evaporation of those solvents has to be reduced as much as possible. Therefore, unit operations such as extraction and adsorption should be integrated even though the optimal solvent for okara had not been equal to the optimal solvent for adsorption.

The sustainability analysis of the extraction process, ${ }^{28}$ the natural water-solubility of part of the present isoflavone forms, but mainly the requirement of integrating the subsequent processing step of purification in the overall design, lead to the conclusion that water should be used for extraction. Nevertheless, the water extract as described above is not suitable for a packed bed chromatographic process: the stream is a suspension of aggregates, mainly of proteins. Therefore, another way of combining extraction and adsorption was evaluated. The same task should be performed, but heuristics can be used to use more suitable mechanisms to do so. For example, we precipitated the proteins that are present in a water extract, but not in the ethanol extract, by lowering the $\mathrm{pH}$ to 4.5. As a result, the clarified extract is suitable for commonly used packed bed chromatographic processes.

Simplified Process Design. Commonly used adsorption processes for purification of minor components have an advantage over liquid-liquid extraction if it comes to (toxic) solvent use. As shown in the previous section, it is possible to purify the isoflavones present in okara with few processing steps, and relatively environmental-friendly solvents (the used mechanisms this process is based on are shown in Figure 3c). However, preparing an extract with fully dissolved solids and isoflavones is at the expense of a lower isoflavone yield, would need separate processing steps, generate extra waste (for changing the $\mathrm{pH}$ ), and could possibly lead to further dilution. Therefore, we used a reversed approach, and instead of preparing an extract for packed bed adsorption, we prepared the adsorption bed suitable for use with the unclarified extract to do the extraction and adsorption in one step. This can be done, following a similar approach of Zhang et al., ${ }^{38}$ who used expanded bed adsorption for the recovery of a target compound from a herb suspension.
Figure 4 shows the profile of isoflavones as extracted after $1 \mathrm{~h}$ with water at neutral $\mathrm{pH}$. It can be assumed that all malonylglucosides, and most glucosides were extracted with water, but part of the aglycones will remain in the matrix. ${ }^{29}$ However, with the amount of resin used, around $45 \%$ of glucosides (42\%, 56\%, and $42 \%$ of daidzin, glycetin, and genistin, respectively) and $35 \%$ malonyl-glucosides (32\%, 36\%, and $39 \%$ of malonyldaidzin, malonyl-glycetin, and malonyl-genistin, respectively) were adsorbed onto the resin. Most of these could desorb from the resin with $96 \%$ ethanol.

An interesting phenomenon was observed for the aglycones. The amount that was adsorbed onto the resin was calculated by the difference between the amount that was present after $1 \mathrm{~h}$ of extraction (before resin addition) and the amount present in the solution after adsorption onto the resin. The amount of aglycones in solution after adsorption to the resin was either in the same range as before adsorption, or even slightly higher. This may indicate that either no aglycones adsorbed or that further extraction from the matrix took place during to the adsorption. The presence of the aglycones in the desorbing solvent (Figure 4) confirmed the latter; more aglycones were released from the matrix during adsorption, and around 52\% of aglycones (54\%, 45\%, 57\% of daidzein, glycetein, and genistein, respectively) were desorbed. Therefore, the aglycones have a higher affinity to the adsorbent than to the matrix. The conclusion from this experiment is that it is possible to combine the extraction and the isolation steps into one single step: this avoids problems (e.g., fouling of a packed bed column), and maximizes the yield (by concurrent extraction). It should be mentioned that this is only possible by using a relatively poor solvent: a good solvent would not allow concurrent adsorption, as the isoflavones would remain in the solution. The presence of many other components in the system may reduce the capacity of the resin, resulting in an increased initial amount of resin. However, the resin can be reused and other advantages (e.g., no fouling of a column, increased yield, possible use of extracted okara as animal feed, and reduction of expensive solvents) may compensate for a possibly increased amount of resin. This experiment is a proof of concept that the mechanisms used in common unit operations can be used to make a complex system or process simple. Previously gained knowledge in this research ${ }^{29,30}$ about ionization of the components and their different behavior in water can now be 
used to optimize the process of a combined one-step separation.

After optimization of the process to achieve the maximum yield and desired purity, a final economic evaluation has to be done calculating whether the costs of the process (e.g., resin and water, and the recycling thereof) do not exceed the beforehand calculated economic potential. At this stage, one can only assume that the discussed consideration of okara as byproduct, and a process that uses a considerable smaller amount of solvents and fewer unit operations than conventional processes to produce isoflavones, make this process having economical potential. Though, the amount of resin necessary and its modification discussed below may be crucial.

At a low liquid-to-solid ratio, it should also be possible to extract all isoflavones, if simultaneous adsorption takes place; the solvent is only the carrier, but not the reservoir of the isoflavones. The already dissolved isoflavones adsorb, and the concentration in the water phase decreases, which allows further extraction, as is shown in Figure 4 with the aglycones. A similar approach has been recently suggested for the first time by Galván D'Alessandro et al. ${ }^{39}$ In our approach though, the byproduct does not need any pretreatment, and the adsorbent is fully integrated in the extraction system.

Accurate purity measurements are difficult to achieve due to a low concentration of solids remaining in the ethanol solution for desorption, but taking samples from the desorbing solution from three independent experiments, centrifuging, and measuring solid content resulted in a purity of $7.4 \pm 1.6 \%$, increasing the purity of the isoflavones almost 15 times in a single, unoptimized step. This shows that extraction and concentration is possible in one integrated simple step without many chemicals or resources. Such concentrations of isoflavones would already be acceptable for use as a food ingredient, but the system has great potential for further improvement, and the purity can very likely be increased to a great extent. For example, an increased yield may be obtained with an elevated starting $\mathrm{pH}$, following a low $\mathrm{pH}$ for adsorption; however, this is at the cost of a more complex process, and of the additional chemicals needed to adjust the $\mathrm{pH}$. Second, $96 \%$ ethanol was used here for the regeneration of the resin, but we expect that a lower ethanol concentration might be better. Third, an increased yield due to a larger amount of resin or higher porosity will also positively influence the purity.

The configuration proposed here is a combination of the first three tasks of the task network shown in Figure 3b. By avoiding thinking in unit operations or processing steps that have to be optimized in isolation, one can easier recognize where tasks can be combined and simplified. In this case, the separation process is altered by using an additional phase in the form of the resin, which is done in a form that does not require filtration. On the basis of the information gathered, this process can now be further optimized. As an example, the resin could be adapted to such a process, that is, it should be very porous for a high surface area, but should have a particle size that allows easy separation from the fibers. Alternatively, the resin particles can have a density that differs from the okara matrix to separate them by sedimentation. In addition, the previously gained detailed information on the traditional route will support the optimal design of the integrated extraction-adsorption. In the end, the revised task network comes very close to the first simple task network, which seemed unlikely at the beginning of the process design.
Evaluation of a Strategic/Holistic Approach. As described in the Theory section, the different isoflavone forms show different behavior, depending on their structure and the $\mathrm{pH}$ of the system. This and the previously shown advantages of using a holistic approach lead to the conclusion that the okara processing should not be seen in isolation from the soymilk production that precedes the okara processing. The fate of the isoflavones depends largely on the soymilk extraction process. ${ }^{4041}$ Inactivation of the naturally present $\beta$-glucosidase, short processing times, and moderate temperatures prevent the hydrolysis of the naturally present glycosides of the soybeans into their respective aglycones or acetyl-forms. Because of the different behavior of aglycones and glycosides, further process design depends on the ratio and presence of those components in the okara matrix. One could even design the process of the primary product (soymilk) such that the primary product keeps or improves its consumer acceptance and the byproduct becomes more suitable for further processing and upgrading.

Thermodynamic understanding and quantitative models are crucial during process synthesis. In this case study, though, as in most food-related cases, okara has a highly structured matrix, the behavior of which is difficult to predict because of the many components interacting with each other. In addition, any external influence, be it pressure, temperature, $\mathrm{pH}$, solvents, or other ingredients, can modify the behavior of each component and their interactive relation. Simple models describing a complex system and summarizing experimental data support the understanding of a complex system. ${ }^{29,42}$ The approach and effective solutions for a process synthesis problem can largely depend on the nature of the problem ${ }^{9,43}$ as also shown in this case. A separation process for ingredients requires a slightly different approach than building a food structure. The material structure and composition will determine the presence of thermodynamic (solubility or partitioning) or kinetic (diffusion) limitations, while tasks such as pasteurization or mixing are less important. Adapting process synthesis methodologies from the chemical sector to the food industry will need further adaptation, and requires experimental input, which should possibly be captured in thermodynamic and kinetic models to predict the complex behavior of the system. In case this is not possible, because of the structure and presence of multiple components in the byproduct, it is possible to describe the behavior with empirical models that give a relation between process conditions and extraction behavior.

The collected experimental data and more detailed knowledge on the system enable the revision of the specific levels, and thus prevent the premature fixation of a flow sheet. The use of such methodology greatly supports the creation of additional possibilities and new concepts that can be further explored. Besides, it supports an open mind for unexpected steps in the process design. The creation of tasks, not unit operations, promotes the holistic approach and simplification of the process since it eases their combination. However, the assignment of building task networks and flow sheets requires a team of experts and creativity to apply the so-called heuristics.

Compared to process optimization, process synthesis of a new process aiming at the development of new technologies is slightly more complex since not so many obvious heuristics may be present yet, which leads to the need of more experimental work. Nevertheless, such process synthesis methodology can facilitate the discovery of new process units and simpler processes and thus produces cheaper and more sustainable options. Besides, it directs future research questions 
to generate the relevant knowledge and point out the heuristics needed to complete the process design. The theoretical construction of task networks in combination with theoretical and empirical models and experimental experience with a system support the open-minded thinking process.

\section{CONCLUSION}

Process synthesis methodologies are commonly used to design processes in the chemical industry systematically, but there is no clear strategy fully developed for the food industry. In this work, the strategic design of a new process for the production of isoflavones from the byproduct okara is described.

The use of the process synthesis methodology allowed the generation of feasible alternatives for processing the okara with a focus on more sustainable processing. In this case, the traditional choice of an ethanol-water mixture for the extraction of isoflavones from the okara was shown to be suboptimal for the subsequent isolation step by affinity-based adsorption of the isoflavones to a resin.

The traditional choice of an adsorptive system in the form of a packed bed was shown to be suboptimal as well, when it involves different solvents and necessitates extra polishing steps.

A combined, one-pot extraction and isolation (adsorption) step led not only to the elimination of these problems, but also to an increased extraction yield.

Thus, while the isolated consideration of each process step leads to choices that are not optimal in the next steps, considering the overall system on the level of general transformations, leads to different, globally optimal choices and in this case an even simplified processing system.

\section{AUTHOR INFORMATION}

\section{Corresponding Author}

*Tel.: +31 3174808 52. E-mail: atzejan.vandergoot@wur.nl.

\section{Notes}

The authors declare no competing financial interest.

\section{ACKNOWLEDGMENTS}

The project is carried out within the framework of ISPT (The Netherlands), and is conducted in cooperation with Unilever. The authors would like to thank Nasim Hooshyar for her support and comments as project leader.

\section{REFERENCES}

(1) Laufenberg, G.; Kunz, B.; Nystroem, M. Transformation of vegetable waste into value added products: (A) The upgrading concept; (B) practical implementations. Bioresour. Technol. 2003, 87 (2), 167-198.

(2) Harjo, B.; Wibowo, C.; Ng, K. M. Development of natural product manufacturing processes: Phytochemicals. Chem. Eng. Res. Des. 2004, 82 (A8), 1010-1028.

(3) Hill, M. Chemical Product Engineering-The third paradigm. Comput. Chem. Eng. 2009, 33 (5), 947-953.

(4) Moggridge, G. D.; Cussler, E. L. An introduction to chemical product design. Chem. Eng. Res. Des. 2000, 78 (A1), 5-11.

(5) Wibowo, C.; Ng, K. A. Product-centered processing: Manufacture of chemical-based consumer products. AIChE J. 2002, 48 (6), 12121230.

(6) Wibowo, C.; Ng, K. M. Product-oriented process synthesis and development: Creams and pastes. AIChE J. 2001, 47 (12), 27462767.

(7) Barnicki, S. D.; Siirola, J. J. Process synthesis prospective. Comput. Chem. Eng. 2004, 28 (4), 441-446.
(8) Gopalakrishnan, M.; Ponce-Ortega, J. M.; El-Halwagi, M. M. A systems approach for process simplification through process integration. Chem. Eng. Technol. 2012, 35 (7), 1262-1272.

(9) Grossmann, I. E.; Guillén-Gosálbez, G. Scope for the application of mathematical programming techniques in the synthesis and planning of sustainable processes. Comput. Chem. Eng. 2010, 34 (9), $1365-1376$

(10) Li, X. N.; Kraslawski, A. Conceptual process synthesis: Past and current trends. Chem. Eng. Process. 2004, 43 (5), 583-594.

(11) Michiel Meeuse, F.; Luis, P.; Antonio, E. Process synthesis applied to the food industry. Comput.-Aided Chem. Eng. 2005, 20, 937-942.

(12) Bongers, P. M. M.; Almeida-Rivera, C. Product Driven Process Synthesis Methodology. In 19th European Symposium on Computer Aided Process Engineering; Jezowski, J., Thullie, T., Eds.; Elsevier: The Netherlands, 2009; Vol. 26, pp 231-236.

(13) Gupta, S.; Bongers, P. Bouillon cube process design by applying product driven process synthesis. Chem. Eng. Process. 2011, 50 (1), 915.

(14) Jankowiak, L.; van der Goot, A. J.; Trifunovic, O.; Bongers, P. M. M.; Boom, R. M.; Iftekhar, A. K.; Rajagopalan, S. Applicability of product-driven process synthesis to separation processes in food. Comput.-Aided Chem. Eng. 2012, Vol. 31, 210-214.

(15) Mateos-Aparicio, I.; Redondo-Cuenca, A.; Villanueva-Suarez, M. J.; Zapata-Revilla, M. A.; Tenorio-Sanz, M. D. Pea pod, broad bean pod and okara, potential sources of functional compounds. LWT-Food Sci. Technol. 2010, 43 (9), 1467-1470.

(16) Jankowiak, L.; Trifunovic, O.; Boom, R. M.; van der Goot, A. J. The potential of crude okara for isoflavone production. J. Food Eng. 2014, 124 (0), 166-172.

(17) Del Rio, D.; Rodriguez-Mateos, A.; Spencer, J. P. E.; Tognolini, M.; Borges, G.; Crozier, A. Dietary (poly)phenolics in human health: Structures, bioavailability, and evidence of protective effects against chronic diseases. Antioxid. Redox Signal. 2013, 18 (14), 1818-1892.

(18) Douglas, J. M. A hierarchical decision procedure for process synthesis. AIChE J. 1985, 31 (3), 353-362.

(19) Douglas, J. M. Process synthesis for waste minimization. Ind. Eng. Chem. Res. 1992, 31 (1), 238-243.

(20) Almeida-Rivera, C.; Jain, P.; Bruin, S.; Bongers, P. Integrated product and process design approach for rationalization of food products. In 17th European Symposium on Computer Aided Process Engineering; Plesu, V., Agachi, P. S., Eds.; Elsevier Science Bv: Amsterdam, 2007; Vol. 24, pp 449-454.

(21) Hostrup, M.; Harper, P. M.; Gani, R. Design of environmentally benign processes: Integration of solvent design and separation process synthesis. Comput. Chem. Eng. 1999, 23 (10), 1395-1414.

(22) Murillo-Alvarado, P. E.; Ponce-Ortega, J. M.; Serna-Gonzalez, M.; Castro-Montoya, A. J.; El-Halwagi, M. M. Optimization of pathways for biorefineries involving the selection of feedstocks, products, and processing steps. Ind. Eng. Chem. Res. 2013, 52 (14), $5177-5190$.

(23) Kao, T. H.; Chen, B. H. Functional components in soybean cake and their effects on antioxidant activity. J. Agric. Food Chem. 2006, 54 (20), 7544-7555.

(24) Balisteiro, D. M.; Rombaldi, C. V.; Genovese, M. I. Protein, isoflavones, trypsin inhibitory and in vitro antioxidant capacities: Comparison among conventionally and organically grown soybeans. Food Res. Int. 2013, 51 (1), 8-14.

(25) Kao, T. H.; Lu, Y. F.; Hsieh, H. C.; Chen, B. H. Stability of isoflavone glucosides during processing of soymilk and tofu. Food Res. Int. 2004, 37 (9), 891-900.

(26) ChemAxon. www.chemicalize.org (accessed 25.02.2014).

(27) Galanakis, C. M. Recovery of high added-value components from food wastes: Conventional, emerging technologies and commercialized applications. Trends Food Sci. Technol. 2012, 26 (2), $68-87$.

(28) Jankowiak, L.; Jonkman, J.; Rossier-Miranda, F. J.; van der Goot, A. J.; Boom, R. M. Exergy driven process synthesis for isoflavone recovery from okara. Energy 2014, 74 (0), 471-483. 
(29) Jankowiak, L.; Kantzas, N.; Boom, R; van der Goot, A. J. Isoflavone extraction from okara using water as extractant. Food Chem. 2014, 160 (0), 371-378.

(30) Méndez Sevillano, D.; Jankowiak, L.; Van Gaalen, T. L. T.; Van Der Wielen, L. A. M.; Hooshyar, N.; Van Der Goot, A. J.; Ottens, M. Mechanism of isoflavone adsorption from okara extracts onto foodgrade resins. Ind. Eng. Chem. Res. 2014, 53 (39), 15245-15252.

(31) Preedy, V. R. Isoflavones: chemistry, analysis, function and effects; Royal Society of Chemistry: Cambridge, 2013.

(32) Hilaly, A. K.; Sandage, B.; Soper, J. Process for producing high purity isoflavones. U.S. Patent No. US7524526, 2009.

(33) Kelly, G. E.; Huang, J. L.; Deacon-Shaw, M. G.; Waring, M. A. Preparation of isoflavones from legumes. U.S. Patent No. US6146668, 2000.

(34) Khare, A. B.; Hilbert, B. H. Process for isolating phenolic compounds. U.S. Patent No. US7015339, 2006.

(35) Rostagno, M. A.; Villares, A.; Guillamon, E.; Garcia-Lafuente, A.; Martinez, J. A. Sample preparation for the analysis of isoflavones from soybeans and soy foods. J. Chromatogr. A 2009, 1216 (1), 2-29.

(36) Wu, J. G.; Ge, J. A.; Zhang, Y. P.; Yu, Y.; Zhang, X. Y. Solubility of genistein in water, methanol, ethanol, propan-2-ol, 1-butanol, and ethyl acetate from (280 to 333) K. J. Chem. Eng. Data 2010, 55 (11), 5286-5288.

(37) El-Halwagi, M. M. Sustainable Design through Process Integration: Fundamentals and Applications to Industrial Pollution Prevention, Resource Conservation, And Profitability Enhancement. ButterworthHeinemann: Amsterdam; Boston, 2012.

(38) Zhang, M.; Yang, H.; Chen, X.; Zhou, Y.; Zhang, H.; Wang, Y.; $\mathrm{Hu}, \mathrm{P}$. In-situ extraction and separation of salvianolic acid B from Salvia miltiorrhiza Bunge by integrated expanded bed adsorption. Sep. Purif. Technol. 2011, 80 (3), 677-682.

(39) Galván D’Alessandro, L.; Vauchel, P.; Przybylski, R; Chataigné, G.; Nikov, I.; Dimitrov, K. Integrated process extraction-adsorption for selective recovery of antioxidant phenolics from Aronia melanocarpa berries. Sep. Purif. Technol. 2013, 120 (0), 92-101.

(40) Ishihara, M.; Singh, H.; Chung, G.; Tam, C. Content composition and antioxidant activity of isoflavones in commercial and homemade soymilk and tofu. J. Sci. Food Agric. 2007, 87 (15), $2844-2852$.

(41) Villares, A.; Rostagno, M. A.; Garcia-Lafuente, A.; Guillamon, E.; Martiez, J. A. Content and profile of isoflavones in soy-based foods as a function of the production process. Food Bioprocess Technol. 2011, 4 (1), 27-38.

(42) Charpentier, J. C. Perspective on multiscale methodology for product design and engineering. Comput. Chem. Eng. 2009, 33 (5), 936-946.

(43) Nishida, N.; Stephanopoulos, G.; Westerberg, A. W. A review of process synthesis. AIChE J. 1981, 27 (3), 321-351. 